\title{
Comment/Commentaire
}

\section{Response to The HPV Vaccination Campaign: A Project of Moral Regulation in an Era of Biopolitics}

\author{
Liane Macdonald \\ SHELley DeEKS \\ Carolyn Doyle
}

Connell and Hunt's critique (2010) raises important questions and concerns about human papillomavirus (HPV) vaccination in Canada; we offer a public health perspective on several key issues.

First, the authors question the merit of subsidized, population-based HPV vaccination programs (Connell and Hunt 2010:72), in the context of Papanicolou (Pap) screening availability and declining cervical cancer incidence in Canada. The advent of safe and effective HPV vaccines for the prevention of cervical cancer means that Canadian females can benefit from three complementary modalities to prevent disease and death due to HPV infection and cervical cancer: primary prevention, or vaccination to protect against infection with the two HPV strains responsible for $70 \%$ of cervical cancers; secondary prevention, or Pap screening to detect asymptomatic changes in the cervix due to cervical cancer or its precursors; and tertiary prevention, or surgical or medical treatment of cervical cancer (Franco et al. 2006). Of these modalities, only primary prevention averts the disease entirely. Although clinical services are covered by universal health care in Canada, some individuals and groups face barriers to gaining access to a regular health care provider, or may not be willing or able to visit a health care provider for preventive or therapeutic services. Social inequalities in health care use persist in Canada, including disparities in Pap screening participation (Amankwah et al. 2009; Maxwell et al. 2001; Pottie et al. 2007; Woltman et al. 2007), and adolescents 
have traditionally been difficult to reach (Rand et al. 2007). Since school enrollment is required by law for all children and younger adolescents in Canada, publicly funded voluntary vaccination programs in schools may improve access to vaccines among students who would not otherwise attend a health care clinic (Reynolds et al. 1999). This increases equity of access to HPV prevention for females who may seldom or never receive Pap tests as older adolescents or adults. As the authors note, newcomers, low-income women, and Aboriginal women are among those most likely to be seldom or never screened; these females bear a disproportionate burden of the 1,300 cases of cervical cancer diagnosed each year in Canada (Canadian Cancer Society 2010:88), and could benefit most from school-based HPV vaccination.

Second, the authors contest the urgency of implementing HPV vaccination programs, and the social construction of cervical cancer as an "imminent threat" (Connell and Hunt 2010:69). Vaccines are not approved in Canada until they have been demonstrated to be safe and effective. After a vaccine is approved, an expert committee reviews the vaccine in question and the disease it prevents, and then makes recommendations for its use in Canada. Gardasi $1^{\circledR}$ was licensed in Canada in July 2006; in February 2007, the National Advisory Committee on Immunization (NACI) recommended the vaccine for girls aged 9-13 years, as its efficacy is greatest when given just before a female becomes sexually active (NACI 2007). The time-sensitivity of HPV vaccination for today's young females is underscored by the fact that by 14 or 15 years of age, about $13 \%$ of Canadian adolescents report that they have already had sexual intercourse (Statistics Canada 2008). Approximately 75\% of adults will be infected with HPV over their lifetime and the risk of acquiring HPV is high immediately following the onset of sexual activity (Winer et al. 2003; Kramer et al. 2010). Therefore every year of program delay denies an additional cohort of girls the opportunity to be optimally protected against HPV infection (Wright et al. 2008). The seminal post-SARS "Naylor Report" recommended earmarking federal funds for new vaccines to ensure their timely and equitable implementation across Canada (National Advisory Committee on SARS and Public Health 2003), and three years after the federal government's announcement of $\$ 300$ million for HPV vaccination, all provinces and territories have implemented school-based publicly funded HPV vaccination programs. Some groups have criticized this as rushed, but others urged public funding of universal HPV vaccination soon after NACI released its recommendations for use (Toronto Public Health 2007), and lauded the timely introduction of publicly funded HPV immunization programs (Cancer Care Ontario 2007). 
Third, Connell and Hunt (2010) claim that HPV vaccination in Canada "verges on mandatory" (63) and "manifests itself as anonymous and coercive strategies" (66). It bears clarifying that all HPV vaccination in Canada is voluntary, whether obtained through publicly funded school-based programs, or privately purchased and administered by an individual's health care provider. HPV vaccination is not compulsory for school pupils in any Canadian jurisdiction. The authors correctly note that informed consent from parents is typically required for vaccination of young females in school-based HPV vaccination programs; this is the case for all childhood vaccinations.

Finally, the authors' Foucauldian critique inaccurately portrays public health sexual health education programs for young females in Canada as abstinence-centric (Public Health Agency of Canada 2003); fails to acknowledge the nonjudgmental and empowerment-oriented approaches to sexual health promotion for young females championed by Canadian public health officials and organizations (Public Health Agency of Canada 2003; Toronto Public Health 2010; Vancouver Coastal Health 2010); and conflates promotion of HPV vaccination with ideological promotion of abstinence. This may have led to the authors' misrepresentation of targeted HPV vaccine education and promotion - which aims to facilitate informed choices about HPV vaccination - as the "medico-moralization" of young women's choices about their sexual activity (Connell and Hunt 2010:67).

We encourage the authors to better contextualize future analyses of HPV vaccination policy in Canada by reviewing the multiple components of the analytic framework for vaccine decision making (Erickson et al. 2005) that informed the Canadian Immunization Committee-National Advisory Committee on Immunization's joint endorsement of the current national goal for HPV immunization programs. Their intent was not to moralize or regulate, but simply

to decrease the morbidity and mortality associated with cervical cancer, its precursors and other HPV-related cancers in women in Canada through combined primary prevention (immunization) and secondary prevention (screening) programs. (Canadian Immunization Committee 2007:7)

\section{REFERENCES}

Amankwah, E., E. Ngwakongnwi, and H. Quan. 2009. Why many visible minority women in Canada do not participate in cervical cancer screening. Ethnicity \& Health 14(4):337-49. 
Canadian Cancer Society. 2010. Canadian Cancer Statistics 2010: Table 1a: Actual Data for New Cases of Cancer, 2006. Accessed 30 Jul, 2010. Available at: http://www.cancer.ca/Canada-wide/About $\% 20$ cancer/Cancer $\% 20$ statistics/ /media/CCS/Canada\%20wide/Files\%20List/English\%20files $\% 20$ heading/PDF $\% 20-\% 20$ Policy $\% 20-\% 20$ Canadian $\% 20$ Cancer $\% 20$ Statistics $\% 20-\% 20$ English/Canadian $\% 20$ Cancer $\% 20$ Statistics $\% 202010 \% 20$ -\%20English.ashx.

Cancer Care Ontario. 2007. Statement on the Ontario HPV Vaccination Program. Oct 5. Accessed 30 July 2010. Available at: http://www.cancercare.on.ca/ common/pages/UserFile.aspx?fileId=13090.

Canadian Immunization Committee. 2007. Recommendations on a Human Papillomavirus Immunization Program. Dec. Accessed Jul 30, 2010. Available at: http://www.phac-aspc.gc.ca/publicat/2008/papillomavirus-papillome/pdf/CIC-HPV Recommendations_Final.pdf.

Connell, E. and A. Hunt. 2010. The HPV vaccination campaign: A project of moral regulation in an era of biopolitics. Canadian Journal of Sociology 35(1):63-82.

Erickson, L.J., P. De Wals, and L. Farand. 2005. An analytical framework for immunization programs in Canada. Vaccine 23(19):2470-6.

Franco, E.L., J. Cuzick, A. Hildesheim, and S. de Sanjose. 2006. Chapter 20: Issues in planning cervical cancer screening in the era of HPV vaccination. Vaccine 24(Suppl 3):S3/171-7.

Kramer, M., L. Mollema, G. Smits, H. Boot, H. de Melker, and F.V. der Klis. 2010. Age-specific HPV seroprevalence among young females in the Netherlands. Sexually Transmitted Infections (Jun 2).

Maxwell, C.J., C.M. Bancej, J. Snider, and S.A. Vik. 2001. Factors important in promoting cervical cancer screening among Canadian women: Findings from the 1996-97 national population health survey (NPHS). Canadian Journal of Public Health.Revue Canadienne De Sante Publique 92(2):127-33.

National Advisory Committee on Immunization (NACI). 2007. Statement on human papillomavirus vaccine: An advisory committee statement (ACS). Canada Communicable Disease Report 33(ACS-2):1-31.

National Advisory Committee on SARS and Public Health. 2003. Learning from SARS: Renewal of Public Health in Canada. Oct: 87-89. Available at: http://www.phac-aspc.gc.ca/publicat/sars-sras/pdf/sars-e.pdf.

Pottie, K., P. Janakiram, P. Topp, and A. McCarthy. 2007. Prevalence of selected preventable and treatable diseases among government-assisted refugees: Implications for primary care providers. Canadian Family Physician/ Médecin de famille canadien 53(11):1928-34.

Public Health Agency of Canada. 2003. Canadian Guidelines for Sexual Health Education. Accessed Aug 5, 2010. Available at: http://www.phac-aspc. gc.ca/publicat/cgshe-ldnemss/pdf/guidelines-eng.pdf. 
Rand, C.M., L.P. Shone, C. Albertin, P. Auinger, J.D. Klein, and P.G. Szilagyi. 2007. National health care visit patterns of adolescents: Implications for delivery of new adolescent vaccines. Archives of Pediatrics \& Adolescent Medicine 161(3):252-9.

Reynolds, K., M. Pass, M. Galvin, S. Winnail, K. Harrington, and R. DiClemente. 1999. Schools as a setting for health promotion and disease prevention. Pp. 23-50 in J. Raczynski and R. DiClemente, eds., Handbook of Health Promotion and Disease Prevention. New York: Kluwer Academics.

Statistics Canada. National Longitudinal Survey of Canadian Children and Youth. 2008. Cycle 3 (1998-1999) and Cycle 4 (2000-2001). Accessed Aug 5, 2010. Available at: http://www.statcan.gc.ca/cgi-bin/imdb/p2SV. pl?Function $=$ getInstanceList\&SurvId $=4450 \&$ SurvVer $=1 \&$ InstaId $=1604$ $4 \&$ SDDS $=4450 \&$ lang $=$ en $\& \mathrm{db}=\mathrm{imdb} \& \mathrm{adm}=8 \& \mathrm{dis}=2$.

Toronto Public Health. 2007. Public Funding of Human Papillomavirus (HPV) Vaccine. Jun 21. Accessed Jul 30, 2010. Available at: http://www.toronto.ca/legdocs $/ \mathrm{mmis} / 2007 / \mathrm{hl} /$ bgrd/backgroundfile-5394.pdf.

2010. Sexual Health: Our Philosophy and Guiding Principles. Accessed Aug 5, 2010. Available at: http://www.toronto.ca/health/sexualhealth/ sh_philosophy_and_guiding_principles.htm.

Vancouver Coastal Health. 2010. Health Promotion: Empowering Teens to be Self-Advocates for Sexual Health. Accessed Aug 5, 2010. Available at: http://teensexualhealth.vch.ca/training teens/HP empowering teens advocates sexual health.htm.

Winer, R.L., S.K. Lee, J.P. Hughes, D.E. Adam, N.B. Kiviat, and L.A. Koutsky. 2003. Genital human papillomavirus infection: Incidence and risk factors in a cohort of female university students. American Journal of Epidemiology 157(3):218-26.

Woltman, K.J., and K.B. Newbold. 2007. Immigrant women and cervical cancer screening uptake: A multilevel analysis. Canadian Journal of Public Health/Revue canadienne de santé publique 98(6):470-5.

Wright, T.C., Jr, W.K. Huh, B.J. Monk, J.S. Smith, K. Ault, and T.J. Herzog. 2008. Age considerations when vaccinating against HPV. Gynecologic Oncology 109(2 Suppl):S40-7.

Liane Macdonald MD MSc is completing specialty training in Community Medicine at the Dalla Lana School of Public Health, University of Toronto. She recently completed a placement as a Community Medicine Resident at the Ontario Agency for Health Protection and Promotion.

Shelley Deeks MD MHSc FRCPC FFAFPM is a Medical Epidemiologist at the Ontario Agency for Health Protection and Promotion, and an Associate Professor at the Dalla Lana School of Public Health, University of Toronto. Her areas of expertise are vaccines and vaccine preventable diseases.

Carolyn Doyle BA is completing a Master of Public Policy at the School of Public Policy and Governance, University of Toronto. She recently completed a placement as a Public Policy Student at the Ontario Agency for Health Protection and Promotion. 
